\title{
Multiscale analysis of the contents of palmatine in the Nature populations of Phellodendron amurense in Northeast China
}

\author{
Minglong Sun ${ }^{1} \cdot$ Lijiao $\mathrm{Xu}^{2} \cdot$ Yingli Peng ${ }^{1}$ Tong Liu ${ }^{3}$ Yuhong Zhang ${ }^{1} \cdot$ \\ Zhiqiang Zhou ${ }^{1}$
}

Received: 22 December 2014/ Accepted: 8 August 2015/Published online: 22 December 2015

(C) Northeast Forestry University and Springer-Verlag Berlin Heidelberg 2015

\begin{abstract}
Palmatine is a valuable ingredient in Chinese medicine that is produced by Phellodendron amurense Rupr. The contents of palmatine content in root bark, trunk bark, perennial branch bark, annual branches, and leaves of the trees with different ages and geographies in Northeast China were measured by high-performance liquid chromatography. The contents of palmatine in the barks of root, trunk, and perennial branch were significantly higher than those in annual branches and leaves. The contents of palmatine in trunk bark and root bark from Lesser Khingan Mountains increased with age, which is significantly opposite to other three vegetation types. The contents of palmatine in perennial branch bark, annual bark and leaves had no significant regularity. Moreover, the contents of palmatine in samples of
\end{abstract}

Project funding: This study is supported by Special Fund for ForestryScientific Research in the Public Interest (Grant No. 201104066)

The online version is available at http://www.springerlink.com

Corresponding editor: Zhu Hong

Yuhong Zhang

pzhangyh@126.com

$\triangle$ Zhiqiang Zhou

uwezhou@126.com

Tong Liu

frauliu@126.com

1 Key Laboratory of Forest Ecology of Ministry of Education, Northeast Forestry University, Harbin 150040, People's Republic of China

2 Research Center of Eco-environmental Science, Beijing 100085, People's Republic of China

3 Center for Ecological Research, Northeast Forestry University, Harbin 150040, People's Republic of China root bark, trunk bark, perennial branch bark and annual bark varied significantly with latitude. The nature populations of $P$. amurense growing at low latitude contained significantly more palmatine than those growing at high latitude. These results provide a scientific basis for the reasonable cultivation and efficient utilization of $P$. amurense.

Keywords Content variations - Multiscale analysis . Palmatine $\cdot$ Phellodendron amurense

\section{Introduction}

Phellodendron amurense Rupr. (Rutaceae) is a broad-leaved tree commonly known as the Amur cork tree (Azad et al. 2005; Wang et al. 2009; Chen et al. 2005; Mori and Fuchigami 1995). Phellodendron amurense is now distributed in Northeastern China, Inner Mongolia, the Russian Far East, southern Sakhalin, Korea, and Japan (Fu and Chin 1991). In China, $P$. amurense is mainly distributed in the southeast of the Lesser Khingan, Changbai and Wanda Mountains and in the northern Yanshan Mountains, the extreme north to Great Khingan Mountains. Phellodendron amurense usually exists in forests as secondary species; there are no pure $P$. amurense forests in the nature (Ma and Zhang 2009).

The wood of this traditional medicine species is yellow, flexible and tough with beautiful texture, can be used to make furniture and industrial art. The bark of $P$. amurense is a traditional Chinese medicine with remarkable medicinal value (Yang et al. 2013) that has been widely used in China, Japan and Korea (Garcia et al. 2006; Leu et al. 2006; Ghosh et al. 2010; Mori et al. 1995; Cuellar and Giner 2001) for many years. Isoquinoline alkaloids such as jateorhizine, berberine and palmatine, can be isolated from the bark to be used as anti-inflammatory, antipyretic, and 
antibacterial medicines (Ikuta et al. 1998; Park et al. 2007). As secondary metabolite of $P$. amurense, these three alkaloids are the material bases for the plant to adapt of plant to the environment (Gershenzon 1984; Fraser and Grime 2000; Shelton 2000).

The market demand for the raw bark material of $P$. amurense was more than 2000 Ton in 2010, and it increased by 400 Ton in the following 3 years (Ding 2011). The nature populations was seriously damaged by huge demand. P. amurense was listed (Fu and Chin 1991; Institute of botany, Chinese academy of sciences 1989) and was confirmed as a Class II level national endangered wild plant species by the Chinese government in 1999. The extensive medicinal use of $P$. amurense has raised interest in its cultivation.

Higher plants use a myriad of metabolites to adapt to environmental changes (Hiroaki and Akira 2012). Plant secondary metabolism is a reaction for plant to adapt to the environment, which has evolved as a result of the interactions between plants and biotic and abiotic factors. It plays an important role in the adaptation to environment stress, plant competition and plant co-evolution, and in the defense against insect pests and pathogenic microorganisms. Secondary metabolites have strong correlation with the environment; their synthesis and accumulation in plant are affected by light, temperature, moisture and other factors. Therefore, the same species among different geographic populations may produce different secondary metabolite levels.

The quantities of secondary metabolites in plants, including Phellodendron species, vary among habitats, geographical locations, seasons, and parts of the plant (Liu et al. 2011; Chang et al. 2012; Qin et al. 2012). But, no studies have assessed the variation in palmatine content in $P$. amurense. Therefore, this study attempted to explore how the contents of palmatine in $P$. amurense varied among habitats in Northeast of China. It is aimed to provide a scientific basis for optimal cultivation and efficient utilization of $P$. amurense.

\section{Methods and materials}

\section{Sample selection}

Phellodendron amurense mainly is distributed in mountainous regions at the longitudes between 39 and $52^{\circ} \mathrm{N}$ and at altitude between 300 and $1200 \mathrm{~m}$ (Zhou and Chen 1997). Four main vegetation types are distributed and across the cold temperate coniferous forests, temperate coniferous and broad-leaved mixed forest vegetation zones in northeastern China include: $\mathrm{IA}_{3}$, Mongolian oak (Quercus mongolica) and larch (Larix gmelinii) in the Great Khingan
Mountains; IIA ${ }_{1}$, the Korean pine (Pinus koraiensis) mixed forest area in the Lesser Khingan Mountains; $\mathrm{IIB}_{1}$, mixed forest (Pinus densiflora, Larix olgensis, $P$. koraiensis) in the Changbai Mountains; and $\mathrm{IIB}_{3}$, mixed forest (Pinus tabulaeformis, Abies holophylla, P. koraiensis, Q. mongolica) in the Changbai Mountains.

From north to south 15 sampling sites were picked in these four vegetation types (Fig. 1), at latitudes between $49^{\circ} 51^{\prime} 20^{\prime \prime} \mathrm{N}$ (Heihe, Heilongjiang Province) and $40^{\circ} 32^{\prime} 39^{\prime \prime}$ $\mathrm{N}$ (Fengcheng, Liaoning Province), at longitudes between $123^{\circ} 30^{\prime} 34^{\prime \prime} \mathrm{E}$ (Faku, Liaoning Province) and $130^{\circ} 11^{\prime} 11^{\prime \prime} \mathrm{E}$ (Muling, Heilongjiang Province). Generally, all the sampling sites are areas in the boreal continental monsoon climate, with the average annual temperature of $0.97-6.28{ }^{\circ} \mathrm{C}$ and the average annual rainfall of $524.34-775.17 \mathrm{~mm}$. The trees in the sample sites had the diameter at breast height (DBH) of 9 to $40 \mathrm{~cm}$ and used growth cone to divide all the trees into three age classes (10-20, 20-30, and $>30$ years). All the samples were collected from June 17th to July 28th, 2011 and divided into five parts of root bark, trunk bark $(1.3 \mathrm{~m}$ above the ground), perennial branch bark, annual branches and leaves. At least 9 trees were picked in each site and 5 different parts were taken from each tree for sample. Samples were cleaned and dried at $60{ }^{\circ} \mathrm{C}$, powdered by a disintegrator, and then sieved (60-80 mesh). The pulverized samples were stored in sealed desiccators at $4{ }^{\circ} \mathrm{C}$ until use.

\section{Chemicals method}

Reference palmatine was purchased from Sigma-Aldrich (St. Louis, MO). Chromatographic grade acetonitrile was purchased from J \& K Chemical Ltd. (Beijing, China) for high-performance liquid chromatography (HPLC) analysis. All the other reagents of analytical grade were obtained from Beijing Chemical Reagents Co. Ltd. (Beijing, China). Deionized water purified by the Milli-Q water purification system (Millipore, Bedford, MA) was used for preparing and diluting all solutions. All the solvents for HPLC were filtered through a $0.45 \mu \mathrm{m}$ microporous membrane (Guangfu Fine Chemicals Research Institute, Tianjin, China) and degassed by ultrasonication before use.

\section{Preparation of standard solution of palmatine and HPLC analytical conditions}

The standard stock solution of palmatine $(0.1 \mathrm{mg} / \mathrm{mL})$ was prepared in methanol. The standard stock solution was stored at $4{ }^{\circ} \mathrm{C}$, and diluted with methanol to the required concentration before direct analysis by HPLC. The chromatographic system (Waters, Milford, MA) was equipped with Millennium 32 software, a 2996 autosampler, 1525 
Fig. 1 Map of $P$. amurense sample sites in northeast China

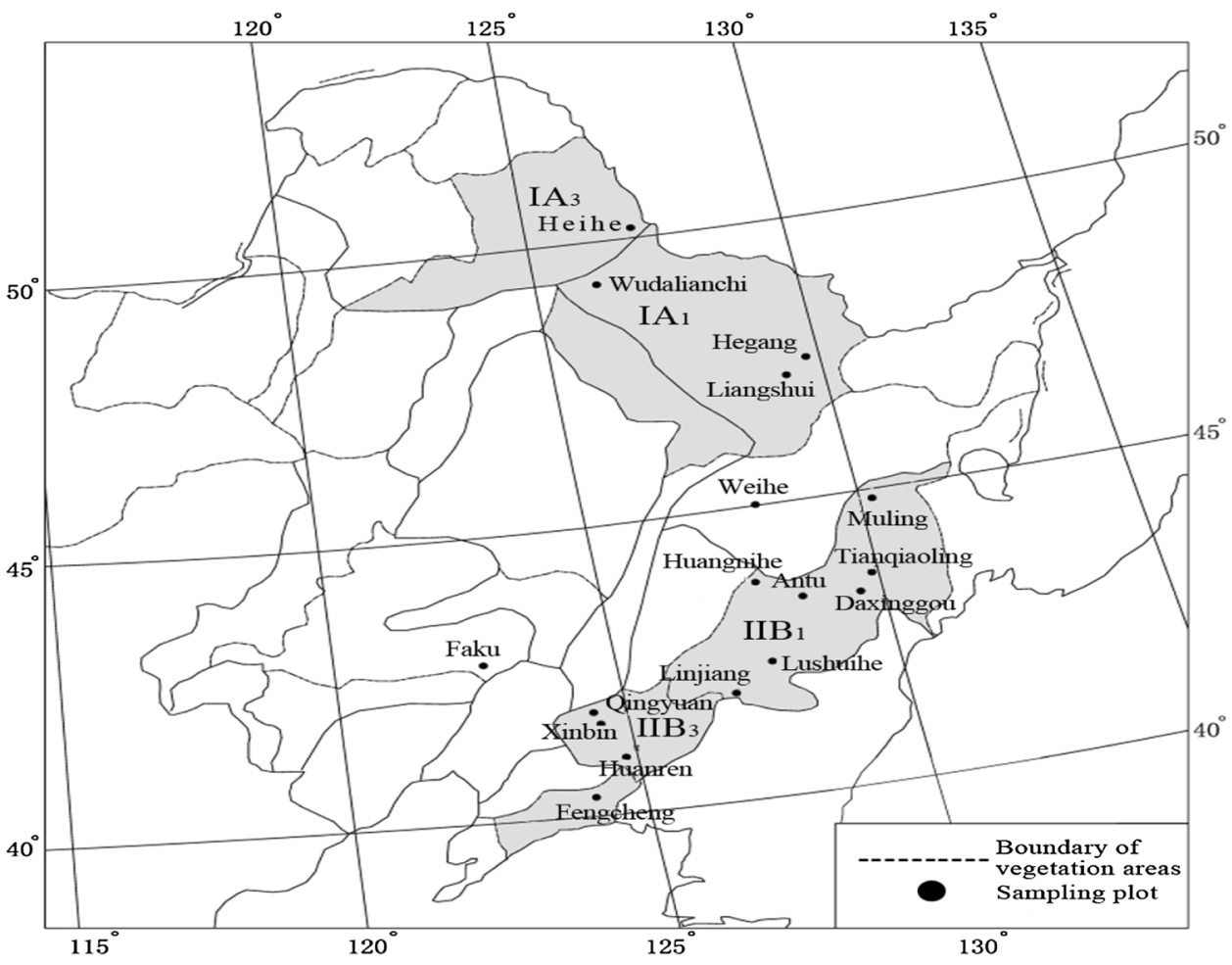

binary pump, 717 automatic column temperature control box and 2487 UV detector. Chromatographic separation was performed on a HiQ sil-C18 reversed-phase column (KYA TECH; $250 \times 4.6 \mathrm{~mm}, 5 \mu \mathrm{m}$ ).

For HPLC analysis, acetonitrile-water $(1: 1, \mathrm{v} / \mathrm{v})$ containing $0.34 \%$ potassium dihydrogen phosphate and $0.17 \%$ sodium dodecyl sulfate was used as the mobile phase, the flow-rate was set at $1.0 \mathrm{~mL} / \mathrm{min}$ and the injection volume was set at $10 \mu \mathrm{L}$, the column temperature was maintained at $25{ }^{\circ} \mathrm{C}$, the absorbance was measured at a wavelength of $345 \mathrm{~nm}$, the run time was $20 \mathrm{~min}$, the retention time of palmatine was $9.7 \mathrm{~min}$. Under these conditions, palmatine was baseline separated. Palmatine was identified by comparing its retention time with the corresponding peak of the standard solution.

\section{Preparation of analytical samples}

Mix $0.1 \mathrm{~g}$ of the dried and powdered plant sample with $4 \mathrm{~mL}$ methanol and pour them into a $25-\mathrm{mL}$ flask. Then put the flask partially into the ultrasound bath (KQ-100 DB, Kunshan, Jiangsu, China) with $2.5 \mathrm{~L}$ water. The water is circulated and regulated at the desired temperature in the ultrasonic bath to maintain the water at a constant temperature for prevent it from being influenced by the ultrasonic exposure. After ultrasonic, the extracts were centrifuged at $12000 \mathrm{r} / \mathrm{min}$ for $10 \mathrm{~min}$ for subsequent HPLC analysis.

\section{Statistical analyses}

Statistical analyses were conducted by SPSS 18.0 (IBM, Chicago, IL, USA). Every palmatine contents of every organ and location were averaged ( \pm standard deviation) and analyzed by one-way analysis of variance (ANOVA) and Tukey's multiple comparison test $(P<0.05)$. The figures were rendered by Excel and Sigmaplot software.

\section{Results}

\section{Palmatine content in different parts of $P$. amurense}

The measured palmatine contents in five parts of $P$. amurense that was collected from its natural distribution in northeastern China in summer 2011 were measured. As is shown in Table 1, the palmatine contents varied greatly in five different parts of $P$. amurense. The sequence of the relative palmatine content levels was: trunk bark $>$ perennial branch bark $>$ root bark $>$ annual branches $>$ leaves. The maximum value of palmatine content in trunk bark reached $17.67 \mathrm{mg} / \mathrm{g}$, which was 10.71 times of its minimum value and also had the highest standard deviation. The other two parts with SD $>2 \mathrm{mg} / \mathrm{g}$ were perennial branch bark and root bark. Although leaves had the lowest palmatine content in the five parts of $P$. amurense, the maximum value was 18 of times its minimum value. It is 
Table 1 The palmatine content in various parts of Phellodendron amurense

\begin{tabular}{llllll}
\hline Plant part & $\begin{array}{l}\text { Number of } \\
\text { samples }\end{array}$ & $\begin{array}{l}\text { Minimum value } \\
(\mathrm{mg} / \mathrm{g})\end{array}$ & $\begin{array}{l}\text { Maximum value } \\
(\mathrm{mg} / \mathrm{g})\end{array}$ & $\begin{array}{l}\text { Mean value } \\
(\mathrm{mg} / \mathrm{g})\end{array}$ & $\begin{array}{l}\text { Standard deviation } \\
(\mathrm{mg} / \mathrm{g})\end{array}$ \\
\hline Root bark & 197 & 0.2 & 12.12 & 2.796 & 2.563 \\
Trunk bark & 188 & 1.65 & 17.67 & 6.293 & 2.615 \\
$\begin{array}{l}\text { Perennial branch } \\
\text { bark }\end{array}$ & 174 & 0.06 & 11.24 & 3.637 & 2.129 \\
$\begin{array}{l}\text { Annual branches } \\
\text { Leaves }\end{array}$ & 156 & 0.65 & 3.02 & 0.908 & 0.631 \\
\hline
\end{tabular}

considered that palmatine content varied greatly in different parts of $P$. amurense.

The 15 sample sites were classified into four groups based on the geographical vegetation zones in northeast of China in order to compare the palmatine contents among different vegetation types. Palmatine contents varied among plant parts in four vegetation types (Fig. 2). There was no significant difference in the palmatine content of trunk bark in four vegetation types except Great Khingan Mountains. The palmatine content of perennial branch bark in Northern Changbai Mountains was the highest, it contained $4.39 \mathrm{mg} / \mathrm{g}$, which was 1.2 times of that in Southern Changbai Mountains, 2 times of that in Lesser Khingan Mountains, 2.25 times of that in Great Khingan Mountains. The palmatine content of root bark responded significantly to the vegetation types in the order of Greater Xing'an $>$ Southern Changbai Mountains $>$ Northern Changbai Mountains $>$ Lesser Khingan Mountains. Similar to the palmatine content of perennial branch bark, the annual branch of $P$. amurense trees in Northern Changbai Mountains had the highest palmatine content; it contained $1.17 \mathrm{mg} / \mathrm{g}$ with no significant difference from Lesser Khingan Mountains, 1.6 times that in Southern Changbai Mountains, 3.3 times of that in Great Khingan Mountains.

Generally the palmatine contents of trunk bark in all four vegetation types were significantly the highest. Except that the palmatine content of perennial branch bark in Great Khingan Mountains was lower than that of root bark, the palmatine content of perennial branch bark was higher than that of root bark in the other three vegetation types.

\section{Palmatine content in difference age classes of $P$. amurense from different vegetation types}

The sample trees were classified into three age groups (10-20, 20-30, >30 years; Table 2) according to the actual age measured by growth cone. The palmatine content of trunk bark and root bark increased with age in the samples from Lesser Khingan Mountains (C), (Fig. 3), which was significantly opposite to other three vegetation types. In northern Changbai Mountains (B) and in Great Khingan Mountains (D), the palmatine contents of perennial branch bark were peaked in 20-30 years old class and then decreased; in Lesser Khingan Mountains (C), the palmatine content of perennial branch bark in 10-20 years old class was lowest, there was no significant difference between those in 20-30 years old class and >30 years old class; in Southern Changbai Mountains (A), the palmatine content of perennial branch bark was lowest in 20-30 years old class, that in $>30$ years old class was higher than that in 10-20 years old class. In northern Changbai Mountains (B) and in Great Khingan Mountains (D), the palmatine

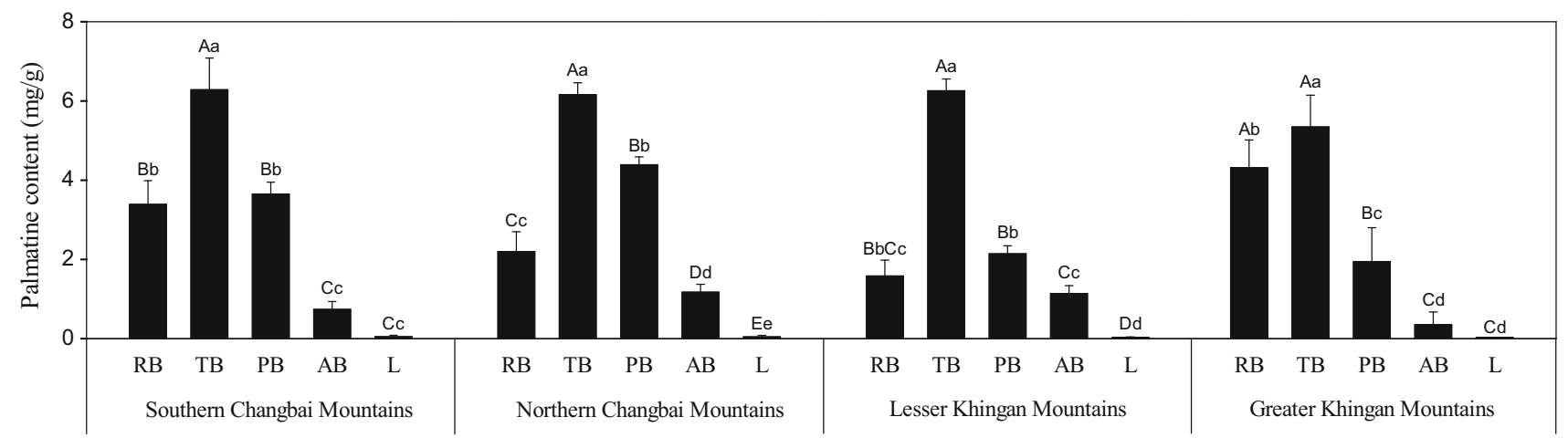

Fig. 2 Palmatine content in different parts of $P$. amurense in of four vegetation types in Northeast of China; $(a)$ RB is root bark; $(b)$ TB is trunk bark; (c) PB is perennial branch bark; $(d) \mathrm{AB}$ is annual bark; $(e) \mathrm{L}$ is leaf 


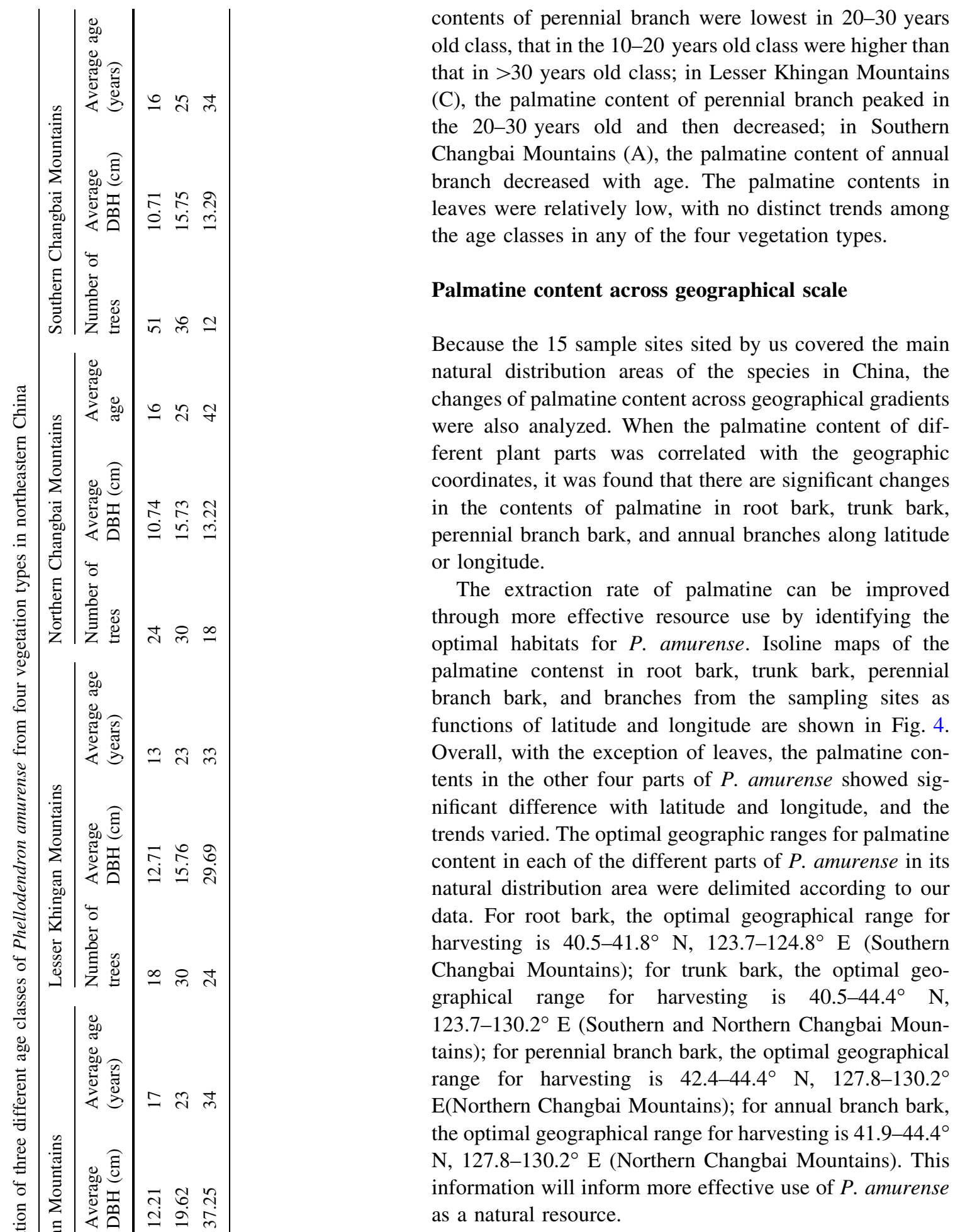

\section{Discussions}

It was proved by previous studies that conspecific plants varied significantly in the synthesis and accumulation of secondary metabolites, which is a universal condition in plants (Dong and Liang 2003). Therefore, multi-scale 

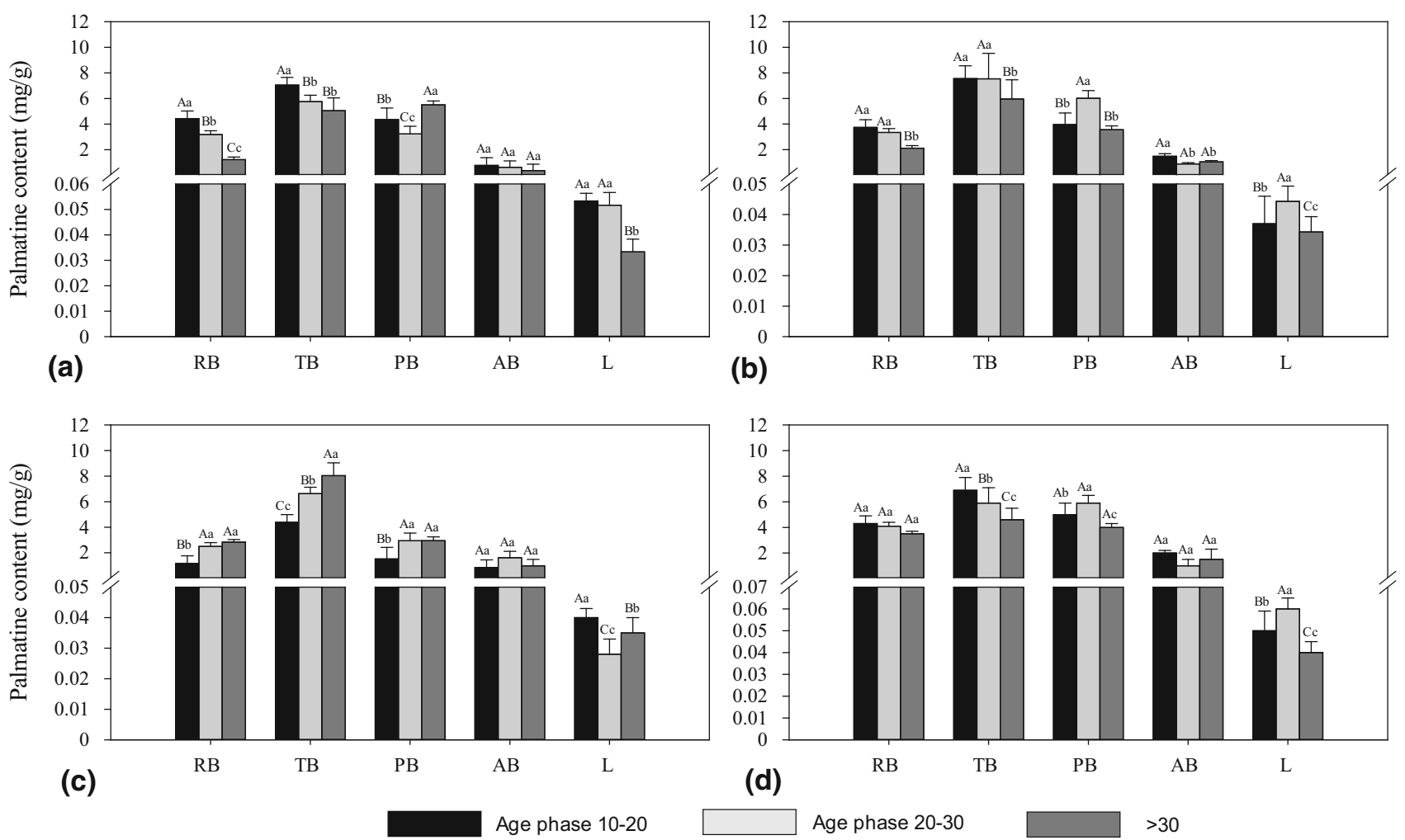

Fig. 3 Palmatine content in different parts of Phellodendron amurense of different age classes. a Southern Changbai Mountains, b Northern Changbai Mountains, c Lesser Khingan Mountains, d Great Khingan Mountains

analyses of palmatine content can help us understand how plant part, age class, and vegetation type impact the distribution of secondary metabolites.

In most of the previous studies on secondary metabolism in $P$. amurense, the raw materials were bought from the market or were seedlings; the samples were not systematically taken from the natural populations; the trends elucidated by the results were not in natural populations. According to these studies, 15 sampled sites covered the main distribution the in natural populations of $P$. amurense in northeast of China. Five plant parts were sampled from the individuals growing in four different vegetation types; palmatine contents varied significantly among plant parts and vegetation types, the palmatine contents in all vegetation types except Great Khingan Mountains generally ranked as trunk bark $>$ perennial branch bark $>$ root bark $>$ annual branches $>$ leaves, similar to result of a previous study (Qin et al. 2004).

In addition to different plant parts, age could also affect alkaloid content. In addition to Lesser Khingan Mountains, the palmatine contents in three age classes of root bark and trunk bark in the other three vegetation types ranked as $(10-20)>(20-30)>(>30$ years). The palmatine contents in three age classes of annual branch bark in three vegetation types ranked as $(20-30)>(10-20)>(>30$ years $)$ but in southern Changbai Mountains they ranked as $(>30)>(10-20)>(20-30$ years $)$.

In addition to plant part and age class, the environment of a plant could have a substantial effect on the synthesis and accumulation of alkaloid, as is shown in the previous studies of plant secondary metabolism ( $\mathrm{Su}$ et al. 2005). Environmental factors such as temperature, moisture, atmosphere, and salinity can have varied impact on the growth of plants, even stress the plant, so that they produce many secondary metabolites to adapt to the environment (Yan et al. 2007); when illumination, temperature, moisture and other environment factors impact the primary growth of plant, they also manipulate the metabolic process of alkaloid (Hashimoto et al. 1994). Depending on the climate data of the four vegetation types sampled in this study (Table 3 ), it was found that the annual mean temperature and annual precipitation dropped gradually from south to north that the frost-free period ( $145 \mathrm{~d}$ ) was longer and accumulated temperature was significant higher at lower latitudes such as the northern Changbai Mountains than at higher latitudes. The better temperature and moisture conditions resulted in more palmatine in the plant parts, which is similar to the result of a previous study (Jiang et al. 2013). In our study, the southern and northern Changbai Mountains had higher annual mean temperature and more annual precipitation 

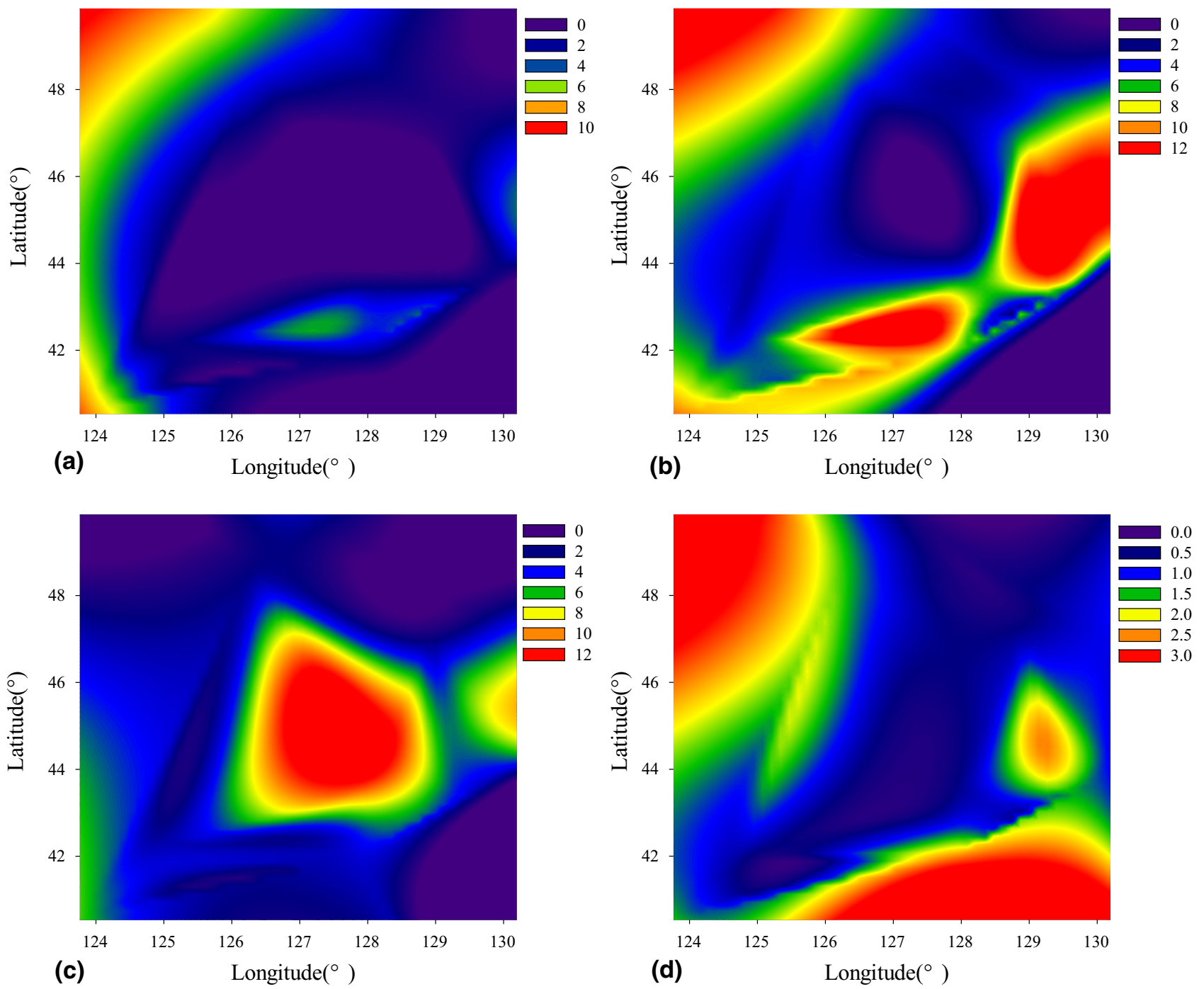

Fig. 4 Isoline plots of palmatine content in different parts of Phellodendron amurense by latitude and longitude. a root bark, b trunk bark, c perennial branch bark, $\mathbf{d}$ annual branches

Table 3 Climate factors of four vegetation types

\begin{tabular}{llllll}
\hline Vegetation type & $\begin{array}{l}\text { Annual mean } \\
\text { temperature }\left({ }^{\circ} \mathrm{C}\right)\end{array}$ & $\begin{array}{l}\text { Annual precipitation } \\
(\mathrm{mm})\end{array}$ & $\begin{array}{l}\text { Annual } \\
\text { sunshine } \\
\text { time (hours) }\end{array}$ & $\begin{array}{l}\text { Accumulated } \\
\text { temperature }\left({ }^{\circ} \mathrm{C}\right)\end{array}$ \\
\hline $\mathrm{IA}_{3}$ & 0.97 & 524.35 & 2690.05 & 2338.15 & $\begin{array}{l}\text { Frost period } \\
(\mathrm{days})\end{array}$ \\
$\mathrm{IIA}_{1}$ & 3.77 & 637.38 & 2399.27 & 2500.70 & 125.05 \\
$\mathrm{IIB} 1$ & 4.27 & 646.45 & 2197.87 & 2413.78 & 150.21 \\
$\mathrm{IIB} 3$ & 6.28 & 775.17 & 2276.91 & 2972.73 & 145.63 \\
\hline
\end{tabular}

$\mathrm{IA}_{3}$ is Great Khingan Mountains; IIA 1 is Lesser Khingan Mountains; IIB ${ }_{1}$ is Southern Changbai Mountains; IIB 3 is Northern Changbai Mountains

than the other two vegetation types, which could explain why there were high palmatine contents in some plant parts at low latitudes. The palmatine isoline plots for different plant parts showed the optimal areas for the raw material of
$P$. amurense and could also guide the selection of superior plants of $P$. amurense in future breeding programs.

The result elucidated that different plant parts, age classes and geographic location affected palmatine content 
in $P$. amurense, but the physiological mechanisms of palmatine production are not well known, so future research must focus on the synthesis and accumulation of $P$. amurense to fully understand these patterns.

\section{Conclusions}

This study elucidated that plant part, tree age, and geography affected the palmatine content in $P$. amurense greatly. Therefore, these parameters must be considered when harvesting plants from nature. It is recommended that the populations of $P$. amurense at lower latitudes such as Northern and Southern Changbai Mountains be encouraged for commercial exploitation and that screening of root, trunk, and perennial branch bark be used to identify elite specimens for harvesting from wild populations.

\section{References}

Azad MAK, Yokota S, Ishiguri F, Yahara S, Yoshizawa N (2005) Histological studies of shoot regeneration system in hypocotylderived callus of Phellodendron amurense Rupr. J For Res 10(5):377-384

Chang Z, Zhou ZQ, Xia CM, Liu T (2012) Characteristics of paclitaxel and cephalomannine content changing in the branches of natural Japanese yew. J Beijing For Univ 34(2):71-77

Chen AH, Lee YT, Chen CY (2005) Microwave accelerated extraction and capillary electrophoresis analysis of berberine from the cortices of Phellodendron wilsonii and Phellodendron amurense. J Chem Soc-Taip 52(4):781-784

Cuellar MJ, Giner RM (2001) Topical anti-inflammatory activity of some Asian medicinal plants used in dermatological disorders. Fitoterapia 72:221-229

Ding L (2011) Trend reviews of Phellodendron amurense. Spec Econ Anim Plant 14:16-18

Dong J, Liang Z (2003) Analysis on the factor influencing secondary metabolite accumulation in plants. Acta Bot Boreali-Occident Sin 24(10):1979-1983

Fraser LH, Grime JP (2000) Aphid fitness on 13 grass species: a test of plant defence theory. Can J Bot 77(12):1783-1789

Fu L, Chin C (1991) China plant red data book: rare and endangered plants, 1st edn. Science Press, Beijing, pp 567-571

Garcia GE, Nicole A, Bhaskaran S, Gupta A, Kyprianou N, Kumar P (2006) Akt-and CREB-mediated prostate cancer cell proliferation inhibition by Nexrutine, a Phellodendron amurense extract. Neoplasia 8(6):523-533

Gershenzon J (1984) Changes in the levels of plant secondary metabolites under water and nutrient stress. Phytochem Adapt Stress 18:273-320

Ghosh R, Graham H, Rivas P, Tan XJ, Crosby K, Bhaskaran S, Schoolfield J, Banu J, Fernandes G, Yeh I-T, Kumar AP (2010) Phellodendron amurense bark extract prevents progression of prostate tumors in transgenic adenocarcinoma of mouse prostate: potential for prostate cancer management. Anticancer Res 30(3):857-865

Hashimoto T, Yamada Y (1994) Alkaloid biogenesis: molecular aspects. Annu Rev Plant Biol 45(1):257-285
Hiroaki S, Akira O (2012) Changes in primary and secondary metabolite levels in response to gene targeting-mediated sitedirected mutagenesis of the anthranilate synthase gene in rice. Metabolites 2:1123-1138

Ikuta A, Nakamura T, Urabe H (1998) Indolopyridoquinazoline, furoquinoline and canthinone type alkaloids from Phellodendron amurense callus tissues. Phytochemistry 48(2):285-291

Institute of botany, Chinese academy of sciences (1989) endangered plant species in China. China Forestry Publishing House, Beijing, pp. 61-65

Jiang Z, Li X, Siping (2013) The effects of climate factors on the principal alkaloid content of Amur Corktree. J Northeast For Univ 40(6):14-18

Leu CH, Li CY, Yao XS, Wu TS (2006) Constituents from the leaves of Phellodendron amurense and their antioxidant activity. Chem Pharm Bull 54(9):1308-1311

Liu T, Chang Z, Wang Y, Zhou Z (2011) Differences in contents of paclitaxel and cephalomannine in Taxus cuspidate of different ages and sexes. J Northeast For Univ 39:51-53

Ma F, Zhang J (2009) Investigation of chinese key protected wild plant resources. China For Publ House, Beijing, pp 77-82

Mori H, Fuchigami M (1995) Principle of the bark Phellodendron amurense to suppress the cellular immune response: effect of Phellodendrine on cellular and humoral immune response. Planta Med 61:45-49

Mori H, Fuchigami M, Inoue N, Nagai H, Koda A, Nishioka I, Meguro K (1995) Principle of the bark Phellodendron amurense to suppress the cellular immune response: effect of phellodendrine on cellular and humoral immune response. Planta Med 61:45-49

Park EK, Rhee HI, Jung HS, Ju SM, Lee YA, Lee SH, Hong SJ, Yang HI, Yoo MC, Kim KS (2007) Antiinflammatory effects of a combined herbal preparation (RAH13) of Phellodendron amurense and Coptis chinensis in animal models of inflammation. Phytother Res 21(8):746-750

Qin Y, Zhang Y, Wang Y, Yan X (2004) Determination of alkaioids content in Phellodendron amurense Rupr. by HPLC. Chem Ind For Prod 24(S1):115-118

Qin BX, Yao LP, Zhou ZQ, Zhang YH (2012) Influence of drought stress on plant physiology and berberine content of leaves in Phellodendron amurense seedlings. $\mathrm{J}$ Beijing For Univ 34(3):26-30

Shelton AL (2000) Variable chemical defences in plants and their effects on herbivore behaviour. Evol Ecol Res 2(2):231-249

Su WH, Zhang GF, Li XH, Qu XK (2005) Relationship between accumulation of secondary metabolism in medicinal plant and environmental condition. Chin Tradit Herb Drugs 36(9):14 Relationship between accumulation of secondary metabolism in medicinal plant and environmental condition. Chin Tradit Herb Drugs 36(9):1415

Wang W, Zu Y, Fu Y, Reichling J, Suschke U, Nokemper S, Zhang Y (2009) In vitro antioxidant, antimicrobial and anti-herpes simplex virus type 1 activity of Phellodendron amurense Rupr. from China. Am J Chin Med 37(01):195-203

Yan XF, Wang Y, Li YM (2007) Plant secondary metabolism and its response to environment. Acta Ecol Sin 27(6):2554-2562

Yang J, Zhao B, Kim YB, Zhou C, Li C, Chen Y, Li CH (2013) Agrobacterium tumefaciens-mediated transformation of Phellodendron amurense Rupr. using mature-seed explants. Mol Biol Rep 40(1):281-288

Zhou Z, Chen XJ (1997) Introduction to the main timber tree species in the world. China Forestry Publishing House, Beijing, pp 87-395 